\title{
Propafenone Poisoning of a Female Adolescent After a Suicide Attempt
}

\author{
Stergiani Keramari ${ }^{1}$, Alexandros Poutoglidis ${ }^{2}$, Frideriki Poutoglidou ${ }^{3}$, Georgia Kaiafa ${ }^{4}$, Michael Keramaris
} 5

1. Second Department of Paediatrics, AHEPA University Hospital, Faculty of Medicine, School of Health Sciences, Aristotle University of Thessaloniki, Thessaloniki, GRC 2. Otorhinolaryngology - Head and Neck Surgery, "G. Papanikolaou" General Hospital, Thessaloniki, GRC 3. Clinical Pharmacology, Faculty of Medicine, School of Health Sciences, Aristotle University of Thessaloniki, Thessaloniki, GRC 4. First Propaedeutic Department of Internal Medicine, AHEPA University Hospital, Faculty of Medicine, School of Health Sciences, Aristotle University of Thessaloniki, Thessaloniki, GRC 5. Cardiology, General Hospital of Kastoria, Kastoria, GRC

Corresponding author: Frideriki Poutoglidou, friderikipa@yahoo.gr

\begin{abstract}
Propafenone is an antiarrhythmic agent for the management of ventricular and supraventricular tachycardia and atrial fibrillation. Propafenone poisoning is rare but may be life-threatening due to drug-induced arrhythmias. Electrocardiographic changes in PR, QRS, and QT intervals have been recorded. We present a case of a 15-year-old female adolescent who developed arrhythmias and convulsions due to propafenone intoxication, in an attempt to commit suicide. The outcome of the case was a full recovery from the arrhythmias and the seizures. The aim of this article is to highlight the possibility of a lethal intoxication by a common antiarrhythmic drug. Our case aims to present our therapeutic strategy that relies mainly on close monitoring of patients and cardiac output support.
\end{abstract}

Review began $07 / 08 / 2021$ Review ended 07/15/2021 Published 07/23/2021

() Copyright 2021 Keramari et al. This is an open access article distributed under the terms of the Creative Commons Attribution License CC-BY 4.0., which permits unrestricted use, distribution, and reproduction in any medium, provided the original author and source are credited.
Categories: Cardiology, Emergency Medicine, Pediatrics

Keywords: seizure, antiarrhythmic agent, propafenone, poisoning, arrhythmia

\section{Introduction}

Propafenone is an antiarrhythmic IC class medication [1-4]. The main indication of the use of propafenone is the prevention of ventricular and supraventricular tachycardia and atrial fibrillation [5]. Patients with structural heart disease are not eligible for treatment with propafenone due to the high risk of developing proarrhythmic events [6].

Overall, propafenone inhibits the action potentials on the cardiac sodium channels. It also inhibits the $\beta$ adrenergic receptors, and the calcium receptors and has a negative inotropic action. Side effects of propafenone include life-threatening electrocardiogram (ECG) anomalies, such as ventricular arrhythmias, ventricular fibrillation or tachycardia, asystole, Torsades de Pointes, and prolongation of the QT or QRS interval [7-8]. Unfortunately, there is currently no known antidote for propafenone intoxication [9].

Propafenone intoxication remains a clinical challenge, even for the most experienced cardiologists. Cases are sparse in literature and a wide range of guidelines have been proposed. Our case report highlights the efficacy of inotropic agents for cardiac function support after propafenone intoxication.

\section{Case Presentation}

A 15-year-old female adolescent was admitted unconscious to our emergency department (ED). On her arrival, generalized tonic-clonic seizures were recorded and a loss of bladder control was observed. The patient's parents reported no history of health issues or substance abuse. Family history was also unremarkable. Intravenous diazepam was administrated at a dose of $1 \mathrm{mg} / \mathrm{kg}$ and a resolution of the convulsions was achieved. Nevertheless, consciousness was not regained.

Physical examination revealed a Glasgow Coma Scale (GCS) of 9/15, a bradycardia (48 bpm), a low blood pressure $(60 / 45 \mathrm{mmHg})$, a respiratory rate of $10 \mathrm{breaths} / \mathrm{min}$, and a temperature of $35.6^{\circ} \mathrm{C}$. Blood glucose level was within the normal range (finger stick $109 \mathrm{mg} / \mathrm{dL}$ ). The initial ECG showed a PR prolongation, a QT prolongation, a QRS prolongation to $170 \mathrm{~ms}$, and a corrected QT interval (QTc) of $490 \mathrm{~ms}$ (Figure 1). The initial arterial blood gases (ABGs) are shown in Table 1. The initial laboratory work-up included a complete blood count $(\mathrm{CBC})$, blood urea nitrogen, serum creatinine levels, and an electrolyte panel, which were all normal. Her chest radiograph was also normal. 


\section{Cureus}

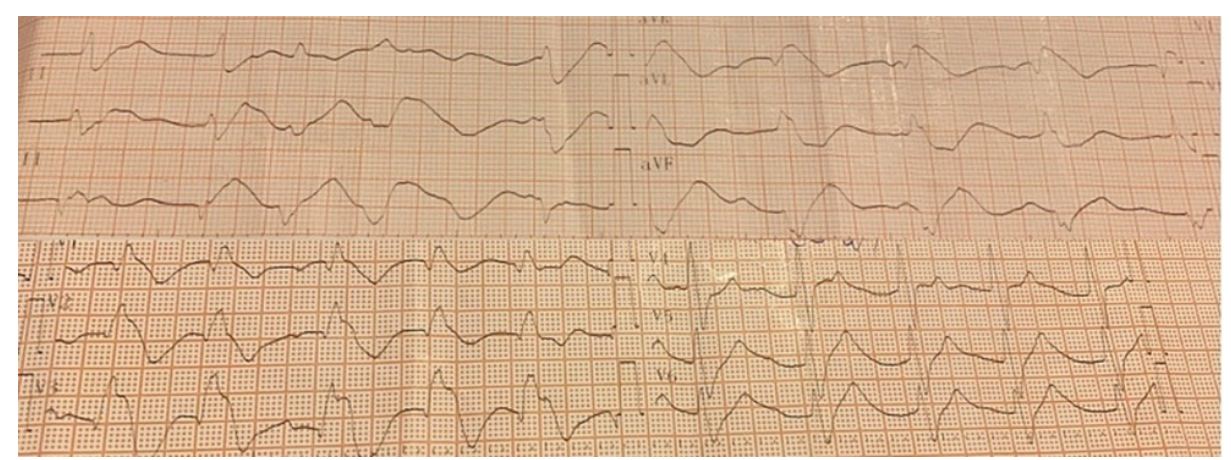

\section{FIGURE 1: The initial ECG.}

PR interval prolongation, QT prolongation, and QRS prolongation to $170 \mathrm{~ms}$ and a corrected QT interval (QTC) of $490 \mathrm{~ms}$

ECG, electrocardiogram

\begin{tabular}{|llll|}
\hline ABGs & On admission & After inotropic agents administration & Five hours later (full recovery) \\
\hline $\mathrm{pH}$ & 7.062 & 7.3 & 7.42 \\
$\mathrm{PCO}_{2}(\mathrm{mmHg})$ & 46.2 & 33.92 & 33.7 \\
$\mathrm{PO}_{2}(\mathrm{mmHg})$ & 69.2 & 90.62 & 82.9 \\
$\mathrm{HCO}(\mathrm{mmol} / \mathrm{L})$ & 13.2 & 16.8 & 22.1 \\
$\mathrm{BE}(\mathrm{mmol} / \mathrm{L})$ & -17.3 & -9.8 & -2.7 \\
\hline
\end{tabular}

\section{TABLE 1: ABGs at different time intervals.}

$B E$, base excess; $A B G s$, arterial blood gases

Oxygen was supplied via a simple face mask at a flow rate of $8-10 \mathrm{~L} / \mathrm{min}$. On the suspicion of opioid or benzodiazepine overdose, naloxone $(0.6 \mathrm{mg})$ and flumazenil $(0.62 \mathrm{mg})$ were administrated intravenously. Two minutes later, the patient regained consciousness but the bradycardia, the hypotension, and the ECG morphology were not improved significantly. The patient reported the consumption of 10 propafenone tablets (225 mg per tablet), which are equivalent to $2250 \mathrm{mg}$, five hours before. Inotropic agents, dopamine (4 $\mu \mathrm{g} / \mathrm{kg} / \mathrm{min}$ ) and dobutamine ( $4 \mu \mathrm{g} / \mathrm{kg} / \mathrm{min}$ ), were administered under close monitoring. The doses were increased at $6 \mu \mathrm{g} / \mathrm{kg} / \mathrm{min}$ of dopamine and $6 \mu \mathrm{g} / \mathrm{kg} / \mathrm{min}$ of dobutamine. The new ABGs are presented in Table 1. One hour after the inotropic agents' administration, an improvement in diuresis was observed. The heart rate increased (65 bpm) and the ECG findings were improved (Figure 2). Five hours later, full recovery was observed. The blood pressure was at $78 / 59 \mathrm{mmHg}$, the heart rate was $80 \mathrm{bpm}$, and the ECG findings (Figure 3) and the ABGs values (Table 1) returned to normal. The patient was discharged $24 \mathrm{~h}$ after admission in excellent condition and was referred to psychiatric consultation. 


\section{Cureus}

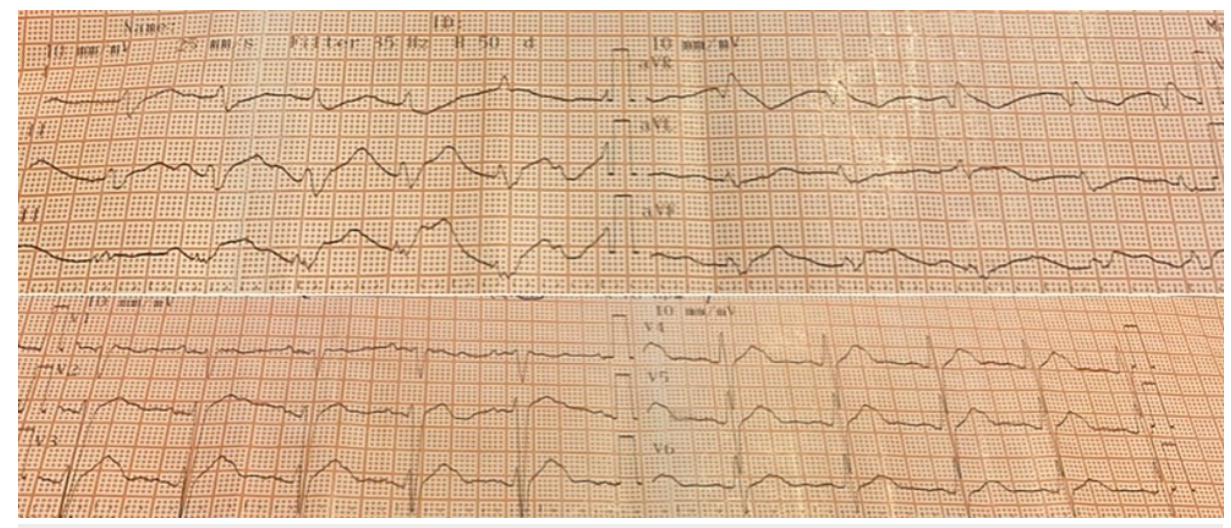

\section{FIGURE 2: ECG after inotropic agent administration.}

PR interval prolongation, QT prolongation, and QRS prolongation to $160 \mathrm{~ms}$ and a corrected QT interval (QTC) of $478 \mathrm{~ms}$

ECG, electrocardiogram

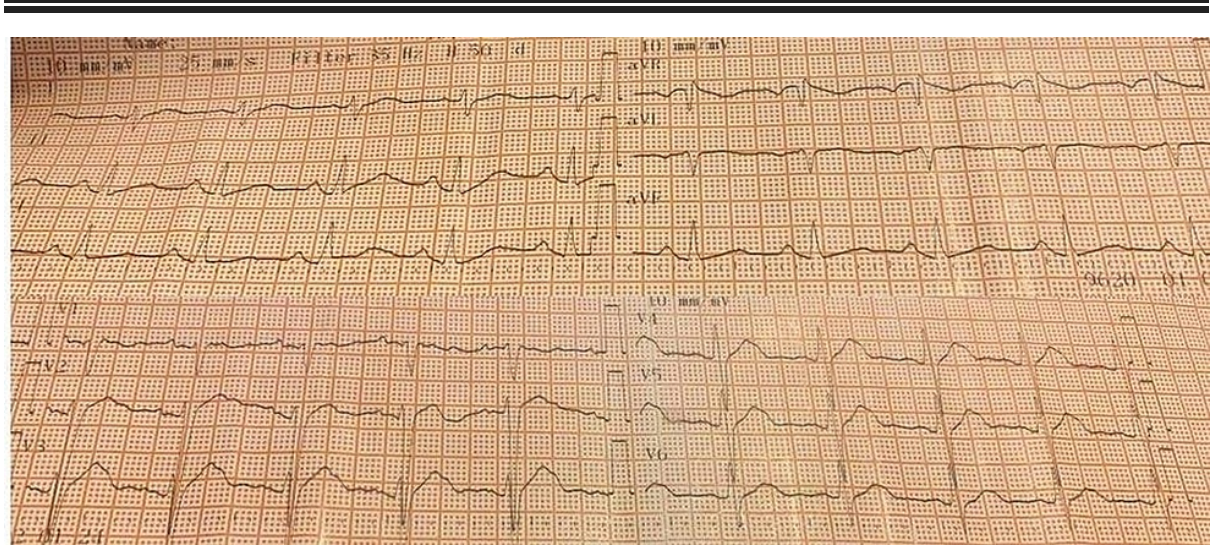

FIGURE 3: ECG after recovery.

PR interval $180 \mathrm{~ms}$, QT and QRS $110 \mathrm{~ms}$, and a corrected QT interval (QTc) of $420 \mathrm{~ms}$

ECG, electrocardiogram

\section{Discussion}

Propafenone is a commonly used antiarrhythmic IC class drug used for the treatment and control of ventricular and supraventricular tachycardia and atrial fibrillation. There are limited data regarding propafenone intoxication which could be explained by the rarity of these cases. Propafenone's mechanism of action mainly relies on the stabilization of the voltage in the myocardial cell membranes by blocking the sodium channels, the $\beta$-adrenergic receptors, and the calcium channels. Propafenone is also characterized by a negative inotropic action [10-11]. The maximum concentration in serum after oral administration is achieved within three to six hours. Following intoxication, the most life-threatening ECG abnormalities are expected to occur within this time interval.

There are two genetically determined patterns of propafenone metabolism. Patients can be categorized either as extensive metabolizers (EMs) or as poor metabolizers (PMs). EMs account for $90 \%$ of the patients. Propafenone is metabolized in 5-hydroxypropafenone from the cytochrome P-450 CYP2D6 isoenzyme and in N-depropylpropafenone from the CYP3A4 and CYP1A2 isoenzymes. Propafenone has a short elimination half-life $(5.5 \pm 2.1 \mathrm{~h})$. PMs, who account for the $10 \%$ of patients, exhibit a decreased action of the isoenzyme CYP2D6 and in those patients, a longer half-life time of propafenone $(17.2 \pm 8 \mathrm{~h})$ has been reported $[5,12$ 14]. Thus, close monitoring over a 24 -h period is required. Previous studies have shown that the $\beta$-blockade effect appears in both phenotypes in a propafenone intoxication; however, the PMs may have a higher propafenone concentration and a greater $\beta$-blockade effect [15]. 
There are several rare adverse effects associated with propafenone, such as allergic reactions, gastrointestinal manifestations, the elevation of liver enzymes, white blood cells disorders (agranulocytosis), headaches, peripheral neuropathy, orthostatic hypotension, ventricular fibrillation, heart failure, and bradycardia. Toxicity of propafenone may lead to coma, cardiac arrest, and arrhythmias (sinus arrest, atrial fibrillation, ventricular tachycardia, prolongation of the PR, QRS, and QT interval widening, Brugada phenocopy, and ventricular fibrillation) [5-7, 14-16]. Propafenone overdose may be fatal [1-4]. Inotropic agents, IV hypertonic bicarbonate, and IV lipid emulsion have been used for the management of propafenone intoxication. Unfortunately, currently, there is neither an antidote nor a specific treatment [17-19]. In our case, tonic-clonic seizures were observed, as a severe neurological manifestation of propafenone intoxication [18]. Seizures are a common sign of propafenone intoxication; however, the reason for the convulsion is unknown. It is unclear whether the seizures are a side effect of the propafenone per se in the central nervous system or it is due to the cerebral hypoperfusion because of the low cardiac output.

\section{Conclusions}

This case report highlights the severity of intoxication by propafenone which can lead to bradycardia, cardiac failure, seizures, loss of consciousness, and potentially death. Immediate treatment, close monitoring and support of the cardiac output are critical for full recovery. Our case report demonstrates that inotropic drugs should be considered as an effective treatment option for the management of propafenone intoxication.

\section{Additional Information \\ Disclosures}

Human subjects: Consent was obtained or waived by all participants in this study. Ethics committee of General Hospital of Kastoria issued approval Not applicable. The present study received an exemption determination by the hospital's Ethics Committee. Conflicts of interest: In compliance with the ICMJE uniform disclosure form, all authors declare the following: Payment/services info: All authors have declared that no financial support was received from any organization for the submitted work. Financial relationships: All authors have declared that they have no financial relationships at present or within the previous three years with any organizations that might have an interest in the submitted work. Other relationships: All authors have declared that there are no other relationships or activities that could appear to have influenced the submitted work.

\section{References}

1. Chen S, Ding W, Ye J, Wang Z, Zhao X, Cui Y: Propafenone-associated gross hematuria: a case report and review of the literature. Clin Ther. 2019, 41:1614-1620. 10.1016/j.clinthera.2019.05.002

2. Funck-Brentano C, Kroemer HK, Lee JT, Roden DM: Propafenone. N Engl J Med. 1990, 322:518-525. 10.1056/NEJM199002223220806

3. Ravid S, Podrid PJ, Novrit B: Safety of long term propafenone therapy for cardiac arrhythmia - expedience with 774 patients. J Electrophysiol. 1987, 1:580-590. 10.1111/j.1540-8167.1987.tb01451.x

4. Wożakowska-Kapłon B, Stępień-Walek A: Propafenone overdose: cardiac arrest and full recovery . Cardiol J. 2010, 17:619-622.

5. Ovaska H, Ludman A, Spencer EP, Wood DM, Jones AL, Dargan PI: Propafenone poisoning - a case report with plasma propafenone concentrations. J Med Toxicol. 2010, 6:37-40. 10.1007/s13181-010-0037-2

6. Boriani G, Biffi M, Capucci A, et al.: Oral propafenone to convert recent-onset atrial fibrillation in patients with and without underlying heart disease. A randomized, controlled trial. Ann Intern Med. 1997, 126:621625. 10.7326/0003-4819-126-8-199704150-00006

7. Srivatsa U, Wadhani N, Singh BN: Mechanisms of antiarrhythmic drug actions and their clinical relevance for controlling disorders of cardiac rhythm. Curr Cardiol Rep. 2002, 4:401-410. 10.1007/s11886-002-0040-6

8. Femenia F, Palazzolo J, Arce M, Arrieta M: Proarrhythmia induced by propafenone: what is the mechanism?. Indian Pacing Electrophysiol J. 2010, 10:278-280.

9. Bayram B, Dedeoglu E, Hocaoglu N, Gazi E: Propafenone-induced cardiac arrest: full recovery with insulin, is it possible?. Am J Emerg Med. 2013, 31:457.e5-7. 10.1016/j.ajem.2012.08.003

10. Hii JT, Duff HJ, Burgess ED: Clinical pharmacokinetics of propafenone. Clin Pharmacokinet. 1991, 21:1-10. 10.2165/00003088-199121010-00001

11. Bryson HM, Palmer KJ, Langtry HD, Fitton A: Propafenone. A reappraisal of its pharmacology, pharmacokinetics and therapeutic use in cardiac arrhythmias. Drugs. 1993, 45:85-130. 10.2165/00003495199345010-00008

12. Köppel C, Oberdisse U, Heinemeyer G: Clinical course and outcome in class IC antiarrhythmic overdose. J Toxicol Clin Toxicol. 1990, 28:433-444. 10.3109/15563659009038586

13. Alsaad AA, Ortiz Gonzalez Y, Austin CO, Kusumoto F: Revisiting propafenone toxicity. BMJ Case Rep. 2017, 2017:bcr-2017-219270. 10.1136/bcr-2017-219270

14. Samaan RA, Sobamowo HO, Tamburrino F, Grodman R, Isber N: Syncope, widened QRS interval, and left ventricular systolic depression: coincident with propafenone therapy for atrial fibrillation. Tex Heart Inst J. 2010, 37:476-479.

15. Lee JT, Kroemer HK, Silberstein DJ, et al.: The role of genetically determined polymorphic drug metabolism in the beta-blockade produced by propafenone. N Engl J Med. 1990, 322:1764-1768. 10.1056/NEJM199006213222502 


\section{Cureus}

16. Odeh M, Seligmann H, Oliven A: Propafenone-induced ataxia: report of three cases. Am J Med Sci. 2000, 320:151-153. 10.1097/00000441-200008000-00016

17. Stancak B, Markovic P, Rajnic A, Petrikova V: Acute toxicity of propafenone in a case of suicidal attempt . Bratisl Lek Listy. 2004, 105:14-17.

18. Clarot F, Goullé JP, Horst M, Vaz E, Lacroix C, Proust B: Fatal propafenone overdoses: case reports and a review of the literature. J Anal Toxicol. 2003, 27:595-599. 10.1093/jat/27.8.595

19. Bayram B, Köse I, Avcı S, Arslan A, Acara Ç: Successful treatment of propafenone intoxication with intravenous lipid emulsion. Pharmacotherapy. 2015, 35:e149-e152. 10.1002/phar.1637 